\title{
Novobiocin Sensitivity of Salmonella typhimurium dam and/or seqA Mutants
}

\author{
ABDELWAHEB CHATTI ${ }^{1 *}$, MERIEM ALOUI ${ }^{2}$, JIHEN TAGOURTI ${ }^{2}$, MOUADH MIHOUB ${ }^{2}$ \\ and AHMED LANDOULSI ${ }^{2}$ \\ ${ }^{1}$ Laboratoire de traitement des eaux usées, Centre des Recherches et Technologies des Eaux, \\ Technopole Borj-cédria, BP 273- Soliman 8020 \\ ${ }^{2}$ Laboratoire de Biochimie et Biologie moléculaire, Faculté des Sciences de Bizerte, Faculté des Sciences de Bizerte, \\ Zarzouna 7021, Université de Carthage, Tunisie
}

Submitted 4 January 2013, revised 22 August 2013, accepted 16 November 2013

\author{
Abstract
}

This study was carried out to determine the effects of novobiocin, a gyrase inhibitor, on the growth, survival, motility and whole cell proteins of $S$. Typhimurium dam and/or seqA strains. Our results showed that the dam and seqA/dam mutants are the most sensitive to novobiocin, compared to wild type and seqA strains. Surprisingly, the motility of seqA mutants increased after exposure to novobiocin only in stationary phase cells. All the other strains showed a significant decrease in their motility. The analysis of protein profiles of all strains demonstrated several modifications as manifested by the alteration of the expression levels of certain bands. Our work is therefore of great interest in understanding the effects of novobiocin on $S$. Typhimurium and the involvement of DNA methylation.

Key words: Salmonella, DNA methylation, seqA, motility, novobiocin, proteins

\section{Introduction}

DNA methylation is a mechanism by which bacteria regulate gene expression and control several cellular processes such as transposition, DNA replication, segregation of chromosomal DNA and mismatch repair. It has been proved that Dam protein regulates gene expression and virulence of $S$. Typhimurium (Heithoff et al., 1999; Balbontin et al., 2006). Indeed, lack of Dam methylation disturbs the expression of std fimbriae. Heithoff et al. (Heithoff et al., 1999) have demonstrated that methylation at specific GATC sequences of promoters is crucial for transcription and alterations in the degree of methylation at promoter sequences may influence gene expression. Dam methyltransferase and regulatory proteins, such as Cap, Lrp, or OxyR compete for overlapping sites in or near promoters (Chatti and Landoulsi, 2008). Oshima et al. (2002) demonstrated that the promoters of most Dam controlled genes contained GATC sequences that overlap with recognition sites for fumarate nitrate reduction (Fnr) and catabolite activator protein (CAP) regulators. These authors suggested that the GATC network regulation takes place upstream of the coding sequences and that it is the consequence of an interaction with a regulatory protein like Fnr or CAP.

Like the Dam methyltransferase, it has been demonstrated that seqA also profoundly affects the transcription of various genes (Lobner-Olesen et al., 2003). In Escherichia coli, the product of the seqA gene is the main negative regulator of chromosome replication initiation (Lu et al., 1994, Slater et al., 1995). SeqA protein binds preferentially to hemi-methylated GATC sites and sequesters the oriC region immediately after replication (Boye et al., 1996). SeqA can also specifically bind to fully-methylated GATC sequences, not only hemimethylated, if regions other than ori $C$ are considered. Our previous results have demonstrated that lack of seqA attenuates the virulence of $S$. Typhimurium in the mouse model (Chatti et al., 2007). Jakomin et al. (2008) proved that std operon is regulated by SeqA protein. The effect of SeqA on plasmid topology has been also demonstrated (Norunn and Skarstad, 1999). Indeed, it has been shown that the seqA mutation increases negative superhelicity of chromosomal and plasmid DNA (Klungsøyr and Skarstad, 2004). So, these findings may reflect a similar effect of SeqA on chromosome topology.

* Corresponding author: A. Chatti, Laboratoire de Traitement des Eaux Usées, Centre des Recherches et Technologies des Eaux, Technopole Borj-cédria, BP 273- Soliman 8020, Tunisie; phone: 21679325 199; fax: 21679325 802; e-mail: chattiabdel@yahoo.fr 
It was demonstrated that novobiocin (a member of the coumermycin family of antibiotics) inhibits bacterial DNA replication and transcription. Novobiocin inhibits the DNA gyrase (Gellert et al., 1976), an enzyme that catalyzes the ATP-dependent introduction of negative superhelical turns into circular double-stranded DNA. Gyrase is needed for processes that require negatively superhelical DNA, such as DNA replication, transcription, DNA repair, and recombination (Chatterji et al., 2001). Also, it has been reported that novobiocin affects membrane integrity, nucleic acid synthesis, and cell wall synthesis (Smith and Davis, 1967).

In this study, we investigated the effects of novobiocin treatment on the survival, motility and whole cell proteins of seqA and/or dam mutants of $S$. Typhimurium.

\section{Experimental}

\section{Materials and Methods}

Bacterial strains and growth conditions. Bacterial strains used in this study, derived from the wild type strain S. Typhimurium 14028 are SV1610 (dam228::MudJ) SV4752 ( $\Delta$ seqA1) and SV4784 (dam225::MudJ/AseqA1) (Jakomin et al., 2008). Overnight cultures of Salmonella were grown in nutrient broth (NB) medium and diluted into $50 \mathrm{ml}$ of fresh sterile broth medium. Bacteria were routinely incubated in nutrient broth (NB) (Pronadisa, Spain) at $37^{\circ} \mathrm{C}$ overnight with shaking $(200 \mathrm{rpm})$. Novobiocin was added at various concentrations directly to the flask and turbidity was monitored by measuring the optical density at $600 \mathrm{~nm}$ of the medium.

Survival study. The strains to be tested were incubated overnight at $37^{\circ} \mathrm{C}$ in $\mathrm{NB}$. Appropriate dilutions of bacteria $\left(10^{8} \mathrm{cfu} / \mathrm{ml}\right)$ were made in sterile PBS solution buffer containing various concentration of novobiocin or no drug $(0,80,200$ and $400 \mu \mathrm{g} / \mathrm{ml})$ and incubated for 1 to 4 hours at room temperature. At the given time points, $100 \mu \mathrm{L}$ of cultures were plated on Nutrient agar, after which the resulting colonies were counted and the fractional survival was calculated.

Minimal inhibitory concentration (MIC) and minimal bactericidal concentration (MBC) determination by broth dilution. For MIC and MBC determinations, serial dilutions of novobiocin were prepared. The tubes were incubated at $37^{\circ} \mathrm{C}$ overnight with shaking and the highest dilution in which there were no growth was recorded as the MIC. For MBC testing, aliquots $(20 \mu \mathrm{l})$ of broth from tubes containing no growth were plated onto solid medium and again incubated overnight at $37^{\circ} \mathrm{C}$. The highest dilution in which there were no survivors was recorded as the MBC. In the above method, controls for each strain were performed using the sterile liquid medium without novobiocin. All MICs and MBCs were confirmed by triplicate assays.

Motility assays. Bacterial strains were grown in NB broth at $37^{\circ} \mathrm{C}$ overnight with agitation. The bacteria were then diluted 1:100 with fresh $\mathrm{NB}$ and incubated at $37^{\circ} \mathrm{C}$ with shaking. Cells were considered to be in exponential and stationary phases when they reach an optical density of 0.5 and 1 , respectively. Bacterial culture $(50 \mu \mathrm{l})$ was spotted onto an NB plate with $0.3 \%$ agar and incubated at $37^{\circ} \mathrm{C}$. The concentration of novobiocin used to study the motility of all strains was $200 \mu \mathrm{g} / \mathrm{ml}$. The swimming motility was estimated by measuring the diameter of the bacterial zone after incubation at $37^{\circ} \mathrm{C}$ during 24 hours. Media used for swarming consisted of $0.5 \%$ bacto-agar with $8 \mathrm{~g} /$ liter nutrient broth, to which $5 \mathrm{~g} /$ liter glucose was added. Swarm plates were typically allowed to dry at room temperature overnight before being used.

Whole cell proteins extraction. Pellets were resuspended in TRIS buffer $(20 \mathrm{mM}, \mathrm{pH} 7.5)$ containing EDTA ( $5 \mathrm{mM})$ and $\mathrm{MgCl}_{2}(5 \mathrm{mM})$. The cells were lysed by sonication. The cell debris was removed by centrifugation at $14000 \times \mathrm{g}$ for $10 \mathrm{~min}$ at $4^{\circ} \mathrm{C}$. The supernatant containing extracted proteins was stored at $-20^{\circ} \mathrm{C}$ until further analysis. Protein concentration was determined according to the method of Lowry (1959).

Statistical. The experiment was repeated three times, and statistical significance was calculated using Student's $t$ test.

\section{Results}

Effect of novobiocin on the growth of mutants. To study the effect of the novobiocin on Salmonella growth, different concentrations ranging from zero to $400 \mu \mathrm{g} / \mathrm{ml}$ were tested. Compared with the control cell suspensions without novobiocin, we observed a modification of the classical cell growth curves of the different strains. Fig. 1 shows the basic phenomena observed in the inhibition of cell growth by novobiocin. The results showed that the antimicrobial activity of novobiocin increases with concentration. These two mutants do not reach the stationary phase after treatment with novobiocin at a concentration of $400 \mu \mathrm{g} / \mathrm{ml}$. As the novobiocin concentration was increased, so did the duration of the lag phase whereas the rate of the growth after inhibition decreased and the cell density at which stationary phase was entered also decreased. The duration of the lag phase was proportional to the novobiocin concentration and variable according to the different Salmonella strains tested.

Effects of novobiocin on the survival of the mutants. The percentage of strains' survival was fol- 

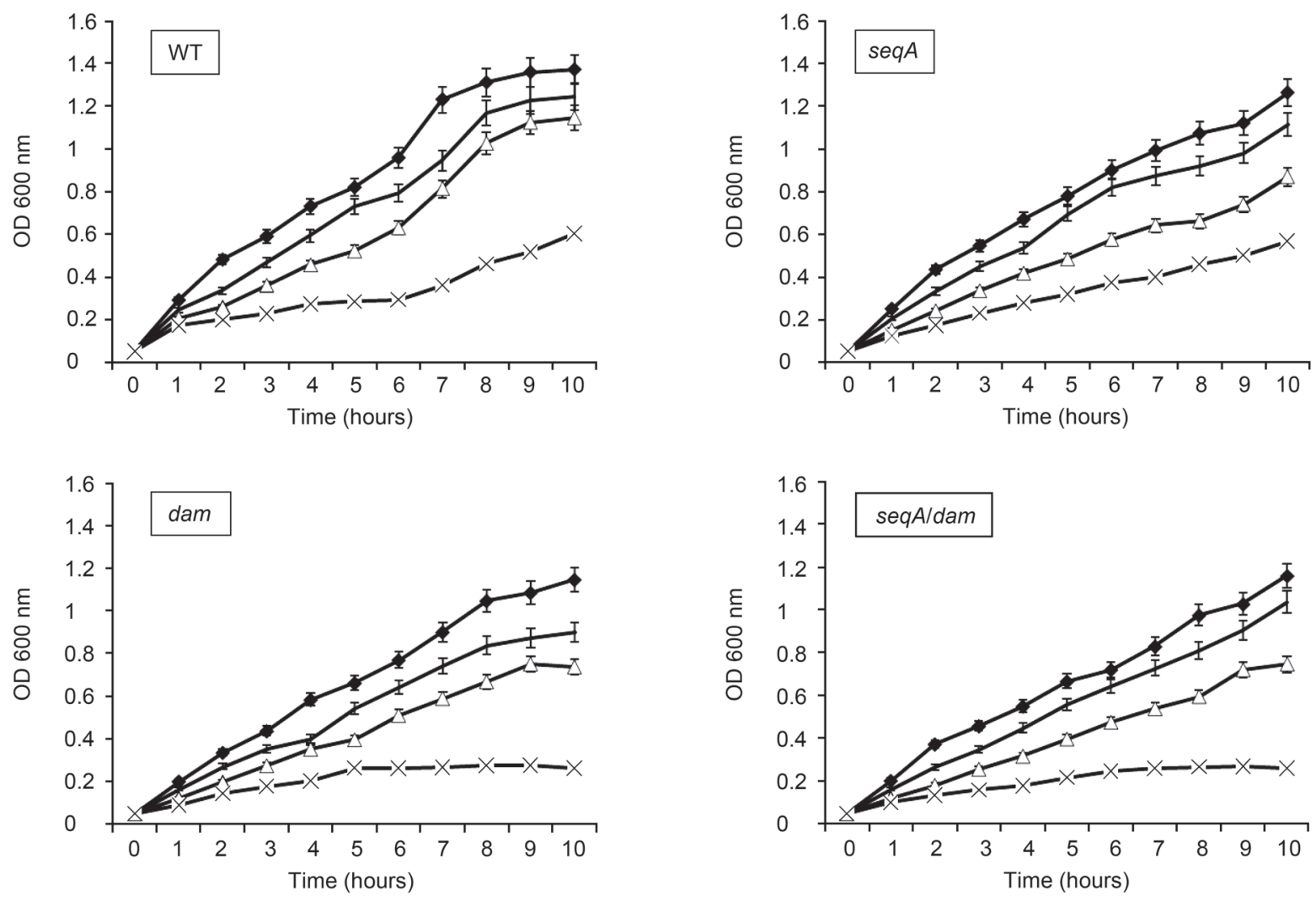

Fig. 1. Growth kinetics of Salmonella typhimurium and its isogenic mutants (dam, seqA and $\operatorname{dam} / \mathrm{seq} A$ ) under different concentrations of novobiocin: $0 \mu \mathrm{g} / \mathrm{ml}$ (black square), 80 (without marker), $200 \mu \mathrm{g} / \mathrm{ml}$ (white triangle) and $400 \mu \mathrm{g} / \mathrm{ml}(\mathrm{X}$ ).

lowed for 4 hours. Control strains were used for comparative study. Significant differences between all strains were mainly observed after treatment during 1 hour. The results obtained showed that the dam and seqA/dam strains are significantly more sensitive to novobiocin, compared to the other strains (Fig. 2). seqA mutant was significantly more resistant than dam and seqA/dam strains.

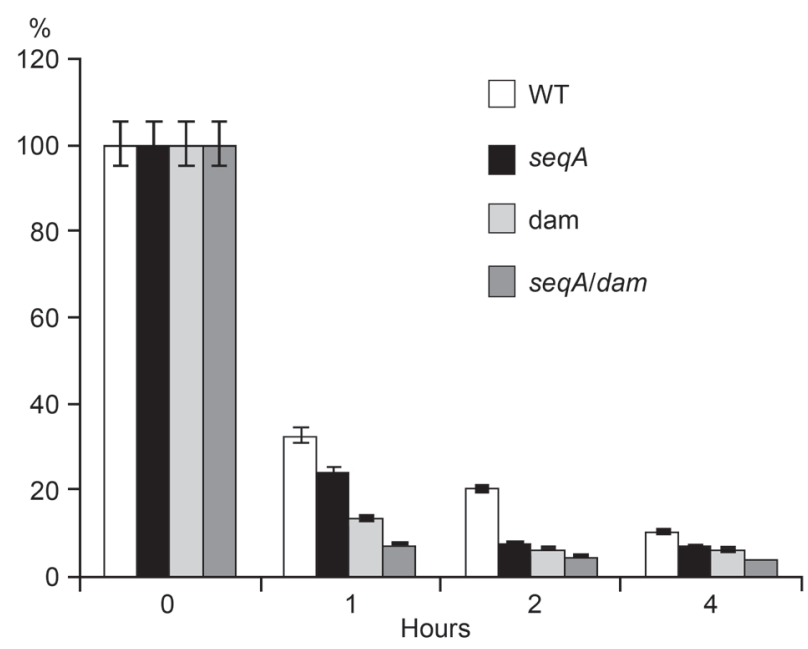

Fig. 2. Novobiocin sensitivity of Salmonella typhimurium and its isogenic seqA and/or dam mutants. Results mentioned are the means of three repetitions. The survival assay was estimated by counting the colony forming units (CFU). The experience was monitored for 4 hours.
Determination of MIC and MBC. The MIC and $\mathrm{MBC}$ values obtained are expressed in terms of the novobiocin concentration (Table I). The MIC values shown were determined by broth dilution. MICs range from 0.6 to $1.1 \mathrm{mg} / \mathrm{ml}$ of novobiocin. The $\mathrm{MBC}$ values range from $2 \mathrm{mg} / \mathrm{ml}$ to $5.6 \mathrm{mg} / \mathrm{ml}$. The double mutant $\operatorname{dam} / \mathrm{seq} A$ presents the lowest $\mathrm{MBC}$ value.

Novobiocin alters the motility of mutants. The motility of novobiocin-treated bacteria was investigated (Fig. 3A). Statistical analysis showed significant differences in the motility of wild type, dam and seqA/dam at exponential phase after drug exposure. At stationary phase, significant difference was observed only in dam and dam/seqA strains (Fig. 3A).

Effect of novobiocin on the whole cell proteins. The whole cell proteins of $S$. Typhimurium and its isogenic mutants were analyzed using SDS-PAGE. When comparing the whole cell preparations on SDS-PAGE,

Table I

MIC and MBC of novobiocin for Salmonella typhimurium (wild type) and isogenic seqA and/or dam mutants

\begin{tabular}{|l|c|c|c|}
\hline & MIC $(\mathrm{mg} / \mathrm{ml})$ & $\mathrm{MBC}(\mathrm{mg} / \mathrm{ml})$ & $\mathrm{MBC} / \mathrm{MIC}$ \\
\hline $\mathrm{WT}$ & $1.1 \pm 0.11$ & $5.6 \pm 0.21$ & 5.09 \\
\hline seq $A$ & $1.1 \pm 0.14$ & $5.0 \pm 0.13$ & 4.54 \\
\hline dam & $0.6 \pm 0.09$ & $2.5 \pm 0.13$ & 4.16 \\
\hline dam $/$ seq $A$ & $0.6 \pm 0.05$ & $2.0 \pm 0.08$ & 3.33 \\
\hline
\end{tabular}



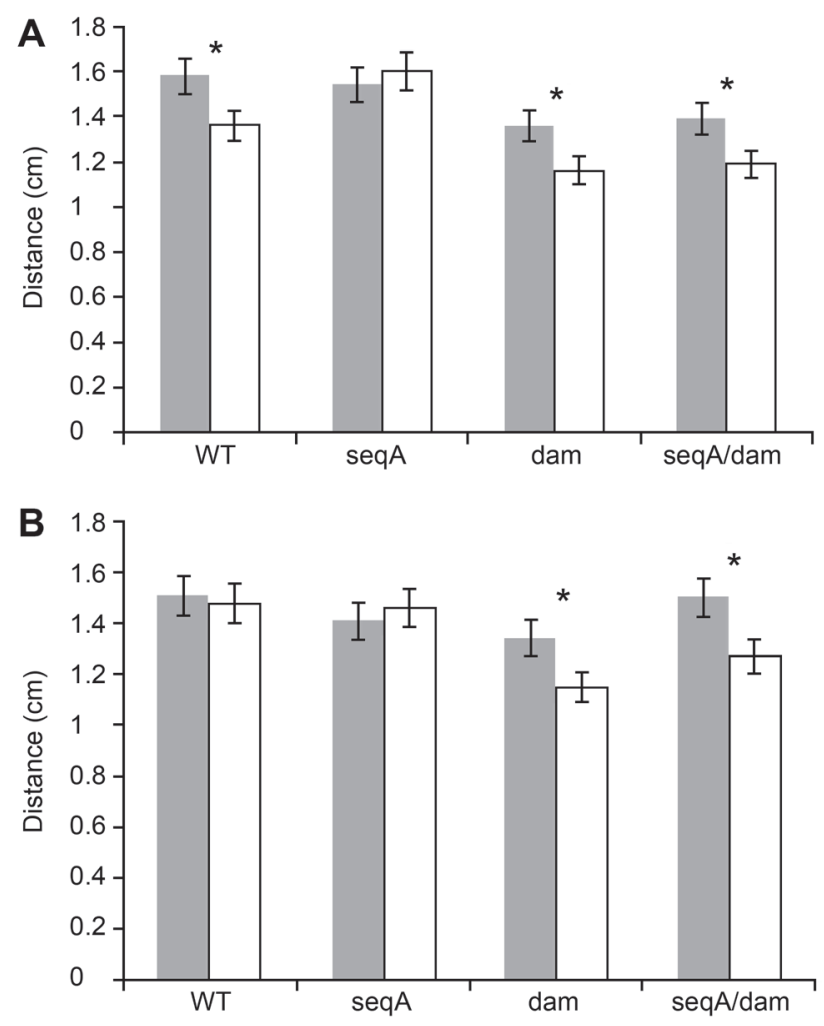

Fig. 3. The motility of exponential (A) and stationary phase (B) cells treated (grey) and untreated (white) strains. * Significant difference $(\mathrm{p}<0.05)$.

changes in protein profiles were observed under the two growth conditions. Therefore, as shown in Fig. 4, changes were manifested either by disappearance or modification of the expression level. In the absence of novobiocin, the alteration of protein profiles of dam and/or seq $A$ was manifested by modification of the expression level of certain bands. After exposure to novobiocin, we noted changes of the expression level

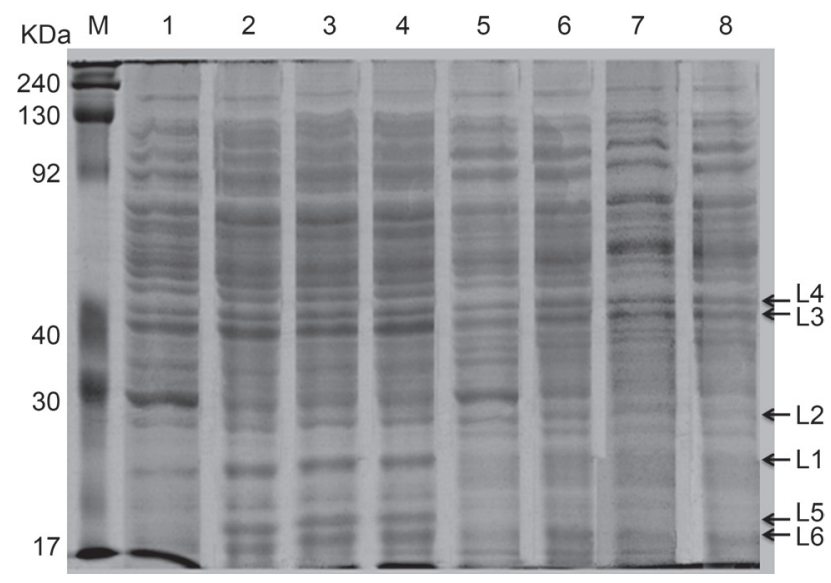

Fig. 4. The whole cell proteins of Salmonella typhimurium and its isogenic dam and/or seqA mutants in the absence (Column 1 to 4 ) or presence (Column 5 to 8 ) of novobiocin. Column 1 and 5: WT, Column 2 and 6: dam: Column 3 and 7: seq A, Column 4 and 8: $d a m / s e q A$. Arrows indicated the lines which show the most bands alterations.
Table II

Ratio of protein levels in each strain before and after drug treatment. Only bands in Line L1 to L6 are analyzed. B: band, the number refers to the column.

\begin{tabular}{|l|c|l|l|l|l|c|}
\hline & L1 & \multicolumn{1}{|c|}{ L2 } & L3 & L4 & L5 & L6 \\
\hline B1/B5 & 1.15 & 1.055 & 1.403 & 1.23 & 1.142 & 1.211 \\
\hline B2/B6 & 1.49 & 1.0001 & 1.220 & 1.042 & 3.05 & 0.607 \\
\hline B3/B7 & 1.27 & 1.0033 & 1.22 & 1.098 & 3.125 & 1.064 \\
\hline B4/B8 & 1.31 & 1.22131 & 1.33 & 1.185 & 3.21 & 1.222 \\
\hline
\end{tabular}

of some proteins for all tested strains. Changes of protein bands are estimated by calculating the ratio of band area before and after novobiocin treatment. Table II shows the changes observed after drug treatment.

\section{Discussion}

It is well known that supercoiling can influence promoter activity (Wang and Lynch, 1993). Thus, DNA supercoiling affects binding of regulatory proteins, such as Dam and SeqA. In our previous work, we suggested that GATC sites could regulate virulence and stress response of $S$. Typhimurium (Chatti and Landoulsi, 2008). The growth of wild-type, dam, seq $A$ and $\mathrm{dam} / \mathrm{seq} A$ mutants were detected in the presence and absence of novobiocin. There was no difference in the growth rates between wild-type and seqA mutant str ains of $S$. Typhimurium in NB medium with or without novobiocin. However, our results showed that the growth of dam and seqA/dam was the most sensitive mutants. Soutourina et al. (2001) have demonstrated that novobiocin (200 and $400 \mu \mathrm{M})$ induces a small decrease of the growth rate for Pseudomonas and Enterobacter. E. coli dam mutant was previously shown to be more sensitive to novobiocin than the wild type strain (Onogi et al., 2000).

To assess the effect of the seqA and/or dam deletions on the in vitro susceptibility to novobiocin, we determined the MICs and MBCs as well as the loss of viable counts after exposure to $400 \mu \mathrm{g} / \mathrm{ml}$ of novobiocin. The MICs of novobiocin were not affected by the seq $A$ inactivation but decreased in dam and seqA/dam strains. The viable losses in time kill experiments confirm also that the seq $A$ mutant is the most resistant compared to the $d a m$ and $d a m / s e q A$. Several studies have proved that dam strains are the most sensitive mutant toward many stresses such as hydrogen peroxide, bile (Chatti et al., 2012; Badie et al., 2007). However, all the mutants were more sensitive than the parent wild type strain. Therefore, novobiocin-induced gyrase inhibition can be expected to cause DNA strand breaks. Hence, it is not surprising that dam mutants, which suffer a basal level of MutHLS-induced DNA breaks, are more sensitive. Bacterial motility is a complex phenotype that is modu- 
lated by many regulators. In this study, we found that seqA mutants did not show significant defects in motility, unlike WT, dam and $d a m / \operatorname{seq} A$ strains under this drug during exponential phase. The stationary culture of these strains demonstrated a significant increase of the motility of seq $A$ mutant and a significant decrease in the motility of both of dam and seqA/dam mutants. However, the motility of WT strain did not change in the stationary phase. These findings suggest the implication of the nucleoid-associated protein FIS which modulate the dynamics of DNA supercoiling during the growth phase (Traversa et al., 2001). Fis promoter is activated by high negative superhelicity of the DNA in vivo and in vitro (Schneider et al., 2000). In addition, it has been proved that CRP-cAMP modulates fis expression and the inhibition of DNA gyrase represses the expression of several CRP-cAMP sensitive genes. Taken together, we can suggest that phase dependant motility especially for seqA mutant could be the consequences of a direct or indirect action of FIS and/or CRP-cAMP (Soutourina et al., 2002). The reduction in motility has been observed in E. coli in the presence of DNA gyrase inhibitors (Schneider et al., 2000). In the presence of novobiocin, a more than two fold decrease in the flhDC activity was obtained in E. coli (Soutourina et al., 2002). Also, inhibiting the DNA gyrase promotes the FimBmediating inversion from OFF to ON and therefore it was concluded that DNA supercoiling determines the directionality of the FimB-mediated recombination (Dove and Dorman, 1994). The decrease of motility in Salmonella in the presence of novobiocin supports the link between the DNA supercoiling and motility regulation. Therefore, motility could be modulated by alteration of DNA topology, resulting from interactions between Dam or SeqA and the regulatory regions.

Whole cell proteins were investigated in the presence or absence of novobiocin. Our results showed that this drug alters the protein profiles of all strains. These changes as manifested by disappearance or modification of the expression levels of several bands. These data suggest that proteins of these strains are associated with growth and survival in the presence of novobiocin. The function of these proteins is subject to further investigation. However, changed proteins could be under the control of CRP-cAMP regulon. Further analysis by $2-\mathrm{DE}$ would be needed for a better separation of proteins and more accurate estimation of sizes and to elucidate their role in bacterial response to novobiocin.

In conclusion, we suggest the involvement of DNA supercoiling on the DNA methylation control of several cellular processes. The difference in the sensitivity toward novobiocin may be due to the fatty acid composition of the membrane of each strain. Further studies on the effects of gyrase inhibitors on virulence genes expression and the deletion of $g y r A$ and/or $g y r B$ in $s e q A$ and/or dam mutants could help researchers to understand the relationship between DNA methylation and DNA supercoiling.

\section{Acknowledgment}

This work was supported by: «Ministère de l'Enseignement Supérieur; Faculté des Sciences de Bizerte-Département de Biologie». We thank Pr. Casadesus J. for providing Salmonella strains.

\section{Literature}

Badie G., D.M. Heithoff, R.L. Sinsheimer and M.J. Mahan. 2007. Altered levels of Salmonella DNA adenine methylase are associated with defects in gene expression, motility, flagellar synthesis, and bile resistance in the pathogenic strain 14028 but not in the laboratory strain LT2. J. Bacteriol. 189: 1556-1564.

Balbontín R., G. Rowley, M.G. Pucciarelli, J. López-Garrido, Y. Wormstone, S. Lucchini, F. García-del Portillo, J.C.D. Hinton and J. Casadesús. 2006. DNA adenine methylation regulates virulence gene expression in Salmonella enterica serovar Typhimurium. J. Bacteriol. 188: 8160-8168.

Boye E., T. Stokke, N. Kleckner and K. Skarstad. 1996. Coordinating DNA replication initiation with cell growth: differential roles for DnaA and SeqA proteins. Proc. Natl. Acad. Sci. USA 93: 12206-12211.

Chatterji M., S. Unniraman, S. Mahadevan and V. Nagaraja. 2001. Effect of different classes of inhibitors on DNA gyrase from Mycobacterium smegmatis. J. Antimicrob. Chemother. 48: 479-485.

Chatti A., D. Daghfous and A. Landoulsi. 2007. Effect of seqA mutation on Salmonella typhimurium virulence. J. Infect. 54: e241-e245. Chatti A. and A. Landoulsi. 2008. The DNA-methylation state regulates virulence and stress response of Salmonella. C.R. Biol. 331: 648-654.

Chatti A., N. Messaoudi, M. Mihoub and A. Landoulsi. 2012. Effect of hydrogen peroxide on the motility, catalase and superoxide dismutase of dam and/or seqA mutant of Salmonella Typhimurium. World J. Microbiol. Biotechnol. 28: 129-33.

Dove S.L. and C.J. Dorman. 1994. The site-specific recombination system regulating expression of the type 1 fimbrial subunit gene of Escherichia coli is sensitive to changes in DNA supercoiling. Mol. Microbiol. 14:975-988.

Gellert M., M.H. O'dea, T. ITOH and J-I. Tomizawa. 1976. Novobiocin and coumermycin inhibit DNA supercoiling catalyzed by DNA gyrase. Proc. Natl. Acad. Sci. USA 73: 4474-4478.

Heithoff D.M., R.L. Sinsheimer, D.A. Low and M.J. Mahan. 1999. An essential role for DNA adenine methylation in bacterial virulence. Science 284: 967-970.

Jakomin M., D. Chessa, A.J. Baumler and J. Casadesus. 2008. Regulation of the Salmonella enterica std Fimbrial Operon by DNA Adenine Methylation, SeqA, and HdfR. J. Bacteriol. 190: 7406-7413. Klungsøyr H.K. and K. Skarstad. 2004. Positive supercoiling is generated in the presence of Escherichia coli SeqA protein. Mol. Microbiol. 54: 123-31.

Lobner-Olesen A., M. Marinus and F. Hansen. 2003. Role of SeqA and Dam in Escherichia coli gene expression: a global microarray analysis. Proc. Natl. Acad. Sci. USA 100: 4672-4677.

Lowry O.H., N.J. Rosenbrough and A.L. Farr. 1951. Protein measurement with the Folin phenol reagent. J. Biol. Chem. 193: 265-275. Lu M., J.L. Campbell, E. Boye and N. Kleckner. 1994. SeqA: a negative modulator of replication initiation in E. coli. Cell 77: 413-426. Norunn K.T. and K. Skarstad. 1999. Escherichia coli SeqA protein affects DNA topology and inhibits open complex formation at oriC. EMBO J. 18: 4882-4888. 
Onogi T., M. Yamazoe, C. Ichinose, H. Niki and S. Hiraga. 2000. Null mutation of the dam or seqA gene suppresses temperaturesensitive lethality but not hypersensitivity to novobiocin of muk null mutants. J. Bacteriol. 182: 5898-5901.

Oshima T., C. Wada, Y. Kawagoe, T. Ara, M. Maeda, Y. Masuda, S. Hiraga and H. Mori. 2002. Genome-wide analysis of deoxyadenosine methyltransferase-mediated control of gene expression in Escherichia coli. Mol. Microbiol. 45: 673-675.

Slater S., S. Wold, M. Lu, E. Boye, K. Skarstad and N. Kleckner. 1995. E. coli SeqA protein binds oriC in two different methyl-modulated reactions appropriate to its roles in DNA replication initiation and origin sequestration. Cell 82: 927-926.

Schneider R., A. Travers and G. Muskhelishvili. 2000. The expression of the Escherichia coli fis gene is strongly dependent on the superhelical density of DNA. Mol. Microbiol. 38: 167-176.
Smith D.H. and B.D. Davis. 1967. Mode of Action of Novobiocin in Escherichia coli. J. Bacteriol. 93:71-79

Soutourina O.A., E.A. Semenova, V.V. Parfenova, A. Danchin and P. Bertin. 2001. Control of Bacterial Motility by Environmental Factors in Polarly Flagellated and Peritrichous Bacteria Isolated from Lake Baikal. App. Environ. Microbiol. 67: 3852-3859.

Soutourina O.A., E. Krin, C. Laurent-Winter, F. Hommais, A. Danchin and P.N. Bertin. 2002. Regulation of bacterial motility in response to low $\mathrm{pH}$ in Escherichia coli: the role of H-NS protein. Microbiology 148: 1543-1551.

Traversa A., R. Schneider and G. Muskhelishvili. 2001. DNA supercoiling and transcription in Escherichia coli : The FIS connection. Biochimie 83:213-217.

Wang J.C. and A.S. Lynch. 1993. Transcription and DNA supercoiling. Curr. Opin. Genet. Dev. 3: 764-768. 